\title{
Combined soil-terrain stratification for characterizing catchment-scale soil moisture variation
}

\author{
Doug Baldwin ${ }^{1}$, Kusum J. Naithani ${ }^{2}$, Henry Lin $^{3 *}$
}

${ }^{1}$ Department of Geography, The Pennsylvania State University, University Park, PA, 16802, USA

${ }^{2}$ Department of Biological Sciences, University of Arkansas, Fayetteville, AR, 72701, USA

${ }^{3}$ Department of Ecosystem Science and Management, The Pennsylvania State University, University Park, PA, 16802, USA

*Corresponding Author, email: henyrlin@ psu.edu, phone: 814-865-6726 
Soil properties and terrain characteristics influence spatiotemporal patterns of soil

3 moisture across a watershed. To improve the predictive power of landscape hydrology models, it

4 is essential to consider both soil and terrain attributes when stratifying a catchment into similar

5 hydrologic functional units. In this study, we developed and validated a new catchment-scale

6 stratification scheme for the Shale Hills watershed by combining soil and terrain attributes in an

7 attempt to delineate soil-landscape units with similar soil moisture dynamics. Terrain was

8 combined with soils information by first using a Random Forest supervised classification

9 algorithm to predict a detailed soil map using 47 field soil samples and terrain variables derived

10 from 1-m LiDAR. A slope class map generated from the LiDAR-derived digital elevation model

11 (DEM) was overlaid on the predicted soil map to delineate areas of similar slope value across the

12 hillslope. We compared the performance of this new stratification scheme with two classical

13 stratification schemes, a soil map developed from detailed field survey and a landform unit map

14 based on the DEM, for estimating soil moisture time-series across the forested watershed. The

15 combined soil-terrain method outperformed classical stratification schemes in estimating soil

16 moisture time-series over a 4-year period. Our results demonstrate that combining soil and

17 terrain attributes can help improve the stratification of a catchment into similar soil hydrologic

18 functional units, which is valuable to distributed hydrology modeling and other applications.

20 Keywords: Soil moisture; Catchment hydrology; Catchment stratification; Terrain attributes;

21 Soil type 


\section{2}

\section{Introduction}

Understanding the link between soil moisture patterns and landscape features is critical to improving landscape hydrologic modeling (Band et al., 1993; Pauwels et al., 2001; Yu et al., 2014). A common assumption in catchment hydrology is that terrain places a dominant control on hydrologic functions (Beven and Kirkby, 1979; Winter, 2001). This assumption leads many researchers to parameterize hydrologic models based on landforms or sub-catchment units using terrain alone. Since topographic information in the form of digital elevation models (DEM) has been increasingly available, stratifying catchments into similar hydrologic functioning units with terrain has been widespread (Moore et al., 1991; Bloschl and Sivapalan, 1995; Winter, 2001). However, field-based soil properties are often not directly included in these stratification schemes, and terrain is assumed to be a proxy for inferring soil properties. These assumptions remain largely unchallenged, since many catchment hydrologic studies do not validate terrainbased sub-catchment units using in situ collected soil moisture data or compare model performance with actual soil distributions.

Topographically-based stratification approaches have been continuously improved over time with advancements in GIS and remote sensing technologies. Following the conceptual work by Beven and Kirkby (1979) and Dooge (1986), hydrologic response units (HRUs) have been developed by dividing a catchment into units of similar topography (Leavesley and Stannard, 1990). Park and van de Giesen (2004) used topographic variables (surface curvature and upslope contributing area) derived from DEM to stratify the Terrawarra Catchment and validated their landform units with a general linear modeling approach using in situ soil moisture measurements. Gharari et al. (2011) used a terrain-based index, called height above nearest 
44 drainage, along with slope value to stratify a catchment in Luxembourg into similar hydrologic 45 functioning units.

Soil properties may have even higher correlations with catchment-wide soil moisture

47 measurements than terrain variables, as Gomez-Plaza et al. (2001) have shown, where sand content was the most correlated variable with soil moisture content for both wet and dry

49 conditions in semi-arid Spain. This suggests that combining soil and terrain attributes within a

50 single stratification would be better for predicting catchment-scale soil moisture dynamics.

51 Temporal patterns of soil moisture have been assessed with terrain and soil characteristics across

52 a watershed (Canton et al, 2004) and some terrain variables are more related to the temporal

53 structure of soil moisture patterns than others. Given this finding, an analysis that addresses how

54 well different terrain variables represent spatio-temporal patterns of soil moisture would be

55 beneficial to any combined soil and terrain stratification study.

There is evidence that combining soil and terrain attributes can further improve

57 catchment hydrologic stratifications (Lin et al., 2006). Takagi and Lin (2012) found that field

58 soil moisture content was highly correlated with terrain variables, depth to bedrock, and clay

59 content in the forested Shale Hills catchment at multiple depths, indicating that both soil and

60 terrain properties are important attributes for defining sub-catchment units with similar soil

61 hydrologic function. Devito et al. (2005) refined existing HRU boundaries by including

62 information about soil texture and peatland cover, which improved catchment water flow

63 predictions. Although a stratification that combines soil and terrain attributes is likely to better

64 characterize catchment-scale soil moisture patterns, a combined soil-terrain stratification in

65 predicting soil moisture patterns has yet to be developed and validated using in situ soil moisture 66 data. 
Given the importance of catchment stratification for scaling soil moisture and

68 parameterizing distributed hydrologic models and the relative scarcity of the validation and

69 comparison of different stratification methods with catchment-wide in situ soil moisture

70 measurements, our objectives in this study are to: (1) uncover terrain variables that are

71 significantly correlated with temporal structure of soil moisture across a catchment, and (2)

72 compare the skill of newly developed soil-terrain stratification scheme with two classical

73 stratifications schemes in predicting catchment-wide soil moisture with in situ data.

74

75

2. Materials and Methods

76

2.1 Study site

77

The Shale Hills Catchment is a 7.9-ha forested watershed characterized by steep slopes

78 (ranging from $25-48 \%$ ) and narrow ridges, with elevation ranging from $256-310 \mathrm{~m}$. The

79 catchment valley is oriented in an east-west direction, which divides the catchment into two

80 almost true north- and south-facing hillslopes. Several species of maple (Acer spp.), oak

81 (Quercus spp.), and hickory (Carya spp.) are typical deciduous trees found on the sloping areas

82 and on the ridges, while the valley floor is dominated by eastern hemlock (Tsuga canadensis

83 Carriére) (Lin, 2006; Naithani et al., 2013). Oaks species are spread throughout the hillslope

84 area, while maples and hickory are mostly situated on the south-facing slope. The climate at the

85 Shale Hills is typical of humid temperate region, with long-term (> $100 \mathrm{yr}$ ) mean monthly

86 temperatures reaching a minimum of $-3{ }^{\circ} \mathrm{C}$ in January and a maximum of $22{ }^{\circ} \mathrm{C}$ in July. Annual

87 precipitation is about $980 \mathrm{~mm}$ (National Weather Service, State College, PA), with the majority 
of precipitation falling as rain during the spring through fall months (about $70-100 \mathrm{~mm} / \mathrm{month}$ ) and as snow in the winter (about $70 \mathrm{~mm} / \mathrm{month}$ ).

The soils at the Shale Hills were formed from Silurian-age shale residuum and colluvium. The soils are generally silt loams and silty clay loams in texture, with some clay loams and sandy clay loams. All soil types have an approximately $0.05 \mathrm{~m}$ thick litter layer (Oe horizon) due to the presence of forested cover over the entire catchment. The catchment is underlain by $>200 \mathrm{~m}$ thick Rose Hill shale, a Silurian formation frequently associated with the iron-rich Clinton Ore. Many gravelly shale fragments $(2-150 \mathrm{~mm})$ are found throughout soil profiles, and the near surface shale is characterized as fractured bedrock.

\subsection{Soil moisture monitoring}

Volumetric soil water content (hereafter, "soil moisture"; unit: $\mathrm{cm}^{3} \mathrm{~cm}^{-3}$ ) was collected manually at a weekly to bi-weekly interval from 106 sites (varied from 46-106 sites depending on the weather and available field assistants) during 2007 - 2010. Soils were drilled down to 1.1 $\mathrm{m}$ or the beginning of bedrock (whichever is shallower), so that $5.1 \mathrm{~cm}$ diameter Schedule 40 PVC tubes could be installed vertically into the soil. During each data collection period, soil moisture was recorded at up to six depths $(10,20,40,60,80,100 \mathrm{~cm})$ using a TRIME-FM Time Domain Reflectometry (TDR) probe (IMKO, Germany), which was inserted within the PVC access tube at each site. Site locations are distributed across the entire catchment (Fig. 1) representing all soil types and landforms and were chosen based on the field surveyed soil map. A total of 17,464 moisture measurements (Weikert $=5,221$, Berks $=3,446$, Rushtown $=4,601$, Blairton $=1,345$, and Ernest $=2,851$ ) were recorded from $2007-2010$ were used in this study. 


\subsection{Field surveyed soil map}

The Hydropedology group at Penn State conducted a detailed soil survey in cooperation with the USDA Natural Resources Conversation Services personnel throughout the catchment (see Lin et al., 2006 for details). Transects were placed $50 \mathrm{~m}$ apart and aligned perpendicularly to the catchment's bedrock southwest to northeast orientation. During the survey, a total of 289 samples were taken, and five soil types were identified in the catchment. Soil thickness, landscape position, and depth to redoximorphic features were the main criteria used to differentiate these soil types.

The Weikert (loamy-skeletal, mixed, active, mesic Lithic Dystrudept) is the predominant soil type in the catchment, comprising $78 \%$ of the catchment, and is characterized as a thin soil on hilltops, planar, and convex hillslopes. The Rushtown (loamy-skeletal, over fragmental, mixed, mesic Typic Dystrochrept) is mostly located in the center of four dominant concave hillslopes and a large portion of the upper $100 \mathrm{~m}$ of the catchment valley. The Berks soil type (loamy-skeletal, mixed, active, mesic Typic Dystrudept) is well drained and largely distributed along the slope transitional zones between the shallow Weikert and the deep Rushtown soils. The Blairton soil type (fine-loamy, mixed, active, mesic Aquic Hapludult) is located in the valley bottom, with an argillic horizon at $0.2-0.8 \mathrm{~m}$ depth and few $(2-5 \%)$ redox features starting at $0.8-1.1 \mathrm{~m}$ depth. The Ernest soil type (fine-loamy, mixed, superactive, mesic Aquic Fragiudults) is a very deep (> $3 \mathrm{~m}$ depth to bedrock), poorly to moderately well-drained soil on the valley floor around the first-order stream with many redox features and a fragipan-like layer starting at $0.3-0.5 \mathrm{~m}$ depth. 


\subsection{Digital terrain, depth to bedrock, and landform units}

A LiDAR flyover in February 2011 was used to generate a high-resolution 1 x 1 m DEM raster dataset for the Shale Hills. During pre-processing, TerraScan software (Terrasolid) classified raw LiDAR point data and ground points were interpolated across space using ordinary kriging (Guo and Si, 2008). A Gaussian filter was applied with a 4.5 x $4.5 \mathrm{~m}$ smoothing window to reduce noise in the DEM. Topographic variables derived from the LiDAR DEM included local slope value (Fig. 2a), vertical distance to stream (VDS, Fig. 2c; Olaya and Conrad, 2009), upslope contributing area (Fig. 2d; Tarboton, 1997), topographic wetness index (TWI, Fig. 2e; Beven and Kirkby, 1979), and surface curvature (Fig. 2f; Zevenberger and Thorne, 1987) using SAGA GIS (Conrad et al., 2015). Local slope value $\left[\mathrm{m} \mathrm{m}^{-1}\right]$, upslope contributing area $\left[\mathrm{m}^{2}\right]$, surface curvature [-], and TWI [-] were developed using the Basic Terrain Analysis module, and VDS [m] was calculated with the Vertical Distance to Channel Network module.

A depth to bedrock map (Fig. 2b) was obtained from catchment-wide auger sampling. A total of 318 auger data points were used in a regression kriging (Isaaks and Srivastava, 1989;

Odeh et al., 1995) to interpolate depth to bedrock across the catchment. During the regression kriging, a backwards-stepwise algorithm (Venables and Ripley, 2002) was used to select a multiple linear regression model with DEM-derived terrain variables as covariates. The regression with the lowest Akaike's Information Criterion (AIC) was selected for regression kriging. The best multiple linear regression model contained surface curvature $(p=0.008)$ and TWI $(p<0.001)$ as covariates.

Park and van de Giesen (2004) developed a stratification method that uses terrain information alone for defining landform units and they validated it with field soil moisture data. We implemented this landform unit stratification method to generate landform units for the Shale 
157 Hills by using the relationship between surface curvature and log-transformed upslope

158 contributing area derived from LiDAR. Variables used in this stratification method are shown in

159 Table 2. It should be noted that Park and Van de Giesen gave planar hillslopes a threshold

160 curvature values of 1 and -1 , which correspond to 0.01 and -0.01 values for the surface curvature

161 in the Shale Hills that were calculated using second-degree polynomial curvature algorithm

162 (Zevenberger and Thorne, 1987).

163

\subsection{Catchment-wide temporal autocorrelation of soil moisture and soil-terrain units}

Terrain variables used in the combined soil and terrain stratification were selected by assessing the correlation of each DEM-derived terrain variable to the temporal autocorrelation of

167 soil moisture at 69 out of 106 sites across the catchment, which were regularly measured from

168 2007-2010. We used the Mantel test (Mantel, 1967) to quantify the temporal autocorrelation at

16969 monitoring locations, at each depth, with long-term data across the watershed using Euclidean

170 distance between the dates of measurements. The Mantel test generates a statistic called Mantel-

$171 \mathrm{r}$ that represents the correlation between two or more distance matrices (Mantel, 1967; McCune

172 and Grace 2002), which in our case are distance matrices of dates of measurements and soil

173 moisture. We used the Spearman rank correlation for correlating the matrices and tested the

174 significance of these correlations with permutation tests in the ecodist library (Goslee and Urban,

175 2007) of the R statistical software environment (R Development Core Team, 2013). Distance-

176 based methods are commonly used in ecological literature (e.g., Legendre and Fortin, 1989;

177 Legendre and Legendre 1998; Uuemaa et al., 2008; Goslee, 2010; Naithani et al., 2014) because

178 they allow incorporation of geographic distances into analyses and do not make assumptions

179 about underlying distributions as significance is tested based on permutation tests (Goslee, 
2010). We replaced geographic distance with temporal distance, particularly to address the uneven temporal gaps (1-2 weeks) in observed data that make it difficult to use the other techniques such as autoregressive models used on time series data analysis.

High Mantel-r values indicate a relatively high dependency of soil moisture from previous dates, where the time-series follows a generally consistent pattern of wetting or drying. Mantel-r values that were significant at $p<0.05$ were then selected for further analysis with terrain variables (58/69 possible Mantel-r values were significant at $10 \mathrm{~cm}, 59 / 66$ at $20 \mathrm{~cm}$, $53 / 59$ at $40 \mathrm{~cm}, 40 / 43$ at $80 \mathrm{~cm}$, and $34 / 36$ at $100 \mathrm{~cm}$ ). To identify predictor terrain variables for use in the combined stratification, the relationship of site-level Mantel-r values at each depth with terrain variables was examined by calculating correlation coefficient for each pair of variables.

As the first step of delineating the combined soil-terrain units, we created a new soil map based upon the high-resolution $(1 \times 1 \mathrm{~m})$ LiDAR-derived terrain and depth to bedrock variables (Fig. 2). Terrain has not been used for directly estimating boundaries of soil type in the Shale Hills catchment, and soil type is at least partially defined by landscape position and depth to bedrock in this catchment (Lin et al, 2006). Soil samples taken during the installation of the 106 TDR monitoring sites provided soil type information for each of these locations, but a subset was used for predicted soil mapping in this study, which consists of the minimum number of samples that can represent different soils in the catchment with the same proportion (number of samples per soil type) as the larger dataset. The locations of these 106 TDR sites in the catchment were based on the representation of soil types and dominant landforms (including hillslope, valley floor, and swale), and the chosen subset of 47 sites also offers a balanced representation of each 
202 soil type within each dominant landform, i.e., valley floor (Ernest, Blairton), swale (Berks, 203 Rushtown), and hillslope (Weikert).

Selected terrain variables that were highly correlated with the temporal autocorrelation of

205 soil moisture across the catchment were used in a Random Forest ensemble supervised

206 classification tree algorithm (Brieman, 2001) to predict soil types. The Random Forest is a

207 machine-learning algorithm that constructs a large number of regression trees, so that a

208 classification estimate from an ensemble of models can be generated. We generated the soil map

209 by building a supervised classification model with both selected terrain variables (independent

210 variables) and soil type (dependent variable).

211 A classification tree was built by first sampling $2 / 3^{\text {rd }}$ of the dataset (out of 47 samples)

212 with an out-of-bag bootstrapping technique, and then a randomly selected subset of predictors

213 was used to fit a decision tree, where a set of rules was assigned to each predictor variable with

214 the objective of minimizing the misclassification of soil type on the sub-dataset chosen with

215 bootstrapping. The bootstrapping and classification tree generation was run for 7000 times, so

216 that a large ensemble of classification trees could be generated. Soil type was then assigned to

217 each data point according to what the majority of classification trees in the ensemble chose. A

218 classification error was calculated on the remaining $1 / 3^{\text {rd }}$ of data not picked with bootstrapping

219 based upon the total number of soil type misclassifications, which was calculated as the

220 proportion of data points misclassified by the algorithm across all ensemble trees. This method

221 makes relatively unbiased estimates of classification error as trees are developed.

222 Terrain variables used in the Random Forest classification were ranked by importance at

223 the end of the algorithm run using a permutation method, where each predictor variable was

224 randomly permuted, while the rest of the predictors were unchanged, and the classification error 
225 was recalculated with the permuted variable. The difference in classification error between the

226 permuted and unchanged variable was calculated for all trees, and the average difference in

227 classification error across all trees defined the 'permutation error difference' measure, which we

228 used to gauge how much each predictor contributed to model accuracy. Higher permutation

229 error difference values indicate that model classification error is higher if a predictor variable is

230 permuted, and the variable with the highest permutation error difference value is the most

231 important variable to include in the model relative to other predictors.

After generating the predicted soil map with terrain variables, we disaggregated the

233 shallow Weikert soil type on the predicted soil map according to slope classes to generate the

234 final combined soil-terrain unit map. The Weikert soil type covers most of the hillside and

235 contains a relatively large variation of slope values compared to the other soil types in the

236 catchment $\left(\right.$ Weikert coverage $=78 \%$, slope range $=0.01-0.51\left[\mathrm{~m} \mathrm{~m}^{-1}\right] ;$ Berks coverage $=10 \%$,

237 slope range $=0.05-0.48\left[\mathrm{~m} \mathrm{~m}^{-1}\right] ;$ Rushtown coverage $=6 \%$, slope range $=0.05-0.40\left[\mathrm{~m} \mathrm{~m}^{-1}\right]$;

238 Blairton coverage $=<1 \%$, slope range $=0.04-0.21\left[\mathrm{~m} \mathrm{~m}^{-1}\right]$; Ernest coverage $=5 \%$, slope

239 range $\left.=0.01-0.29\left[\mathrm{~m} \mathrm{~m}^{-1}\right]\right)$. A map of slope classes was created by using the USDA slope class

240 designations: $\mathrm{A}=0-3 \%, \mathrm{~B}=3-8 \%, \mathrm{C}=8-15 \%, \mathrm{D}=15-25 \%$, and $\mathrm{E} \geq 25 \%$. Slope

241 classes A, B, and C were combined into one 0 - $15 \%$ class, since very little area was represented

242 by these classes in this catchment.

\section{$244 \quad 2.6$ Comparison with classical stratification schemes}

The predictive power of soil moisture variability across the catchment was compared

246 between the combined soil-terrain units and two classical stratification schemes, including: (1)

247 landform unit map and (2) field-surveyed soil map. Soil moisture at all 106 sites was predicted 
248 by each of these stratification schemes in a linear regression model, where the map unit

249 designations were coded as unordered factors. The model set-up is the same for each

250 stratification system, where we used a single factor linear regression:

251

$$
\theta_{t}^{i j}=\beta_{o}+\sum_{j=1}^{n} \beta_{j} U_{j}
$$

252 where $\theta_{t}^{i j}$ is soil moisture content at site $i$ and unit $j$ at measurement date $t, n$ is the total number

253 of units, $\beta_{o}$ is the average soil moisture from all sites in a reference unit (arbitrarily chosen in the

254 model), $\beta_{j}$ is a regression coefficient for the unit $j$ where site $i$ is located, and $U$ is a 'dummy'

255 coding for a particular unit $j$. The $\underline{U}$ coding is ' 1 ' if $\theta^{i j}$ resides within the same unit as $\underline{U}$ and ' 0 '

256 otherwise. This regression setup will provide the same model fit as a single factor analysis of

257 variance (ANOVA), and the $\mathrm{R}^{2}$ is related to the variance of soil moisture within each unit. The

258 difference between a single factor linear regression and an ANOVA is that each category's (i.e.,

259 unit's) mean is compared to the overall mean in an ANOVA, while each category's mean is

260 compared to a reference category's mean in a single factor regression. A categorical system with

261 lower overall variance of soil moisture within its units will have a lower $\mathrm{R}^{2}$ relative to other

262 systems. Separate linear models were developed for each stratification system at each

263 measurement date and for each depth. This allowed the tracking of model performance across

264 time for each depth, since the mean and variation of soil moisture changes within each

265 stratification systems units for across different measurement dates.

266 We used two approaches to analyze the predictive skill of each stratification system's

267 linear model: the Akaike's Information Criterion (AIC) and $\mathrm{R}^{2}$. The AIC value decreases with

268 low mean model error and increases with the number of parameters or categories used. Since the

269 numbers of map-units across the stratification systems differ, the AIC value is a more balanced

270 performance measure for comparison purposes. We subtracted the AIC value associated with 
271 landform units and soil types with the AIC from soil-terrain units to obtain $\triangle \mathrm{AIC}$ values for all 272 measurement dates and soil depths. If $\Delta \mathrm{AIC}$ is less than zero, then soil-terrain units do better 273 when predicting soil moisture patterns. We also plotted the $\mathrm{R}^{2}$ of each linear model over time to 274 assess the raw predictive ability of each stratification system at each depth during the entire 275 measurement period.

277 3. Results and Discussion

In addressing our first objective, we found that the local slope value, upslope contributing

279 area, TWI, elevation, VDS and depth to bedrock variables related significantly $(p<0.05)$ to 280 Mantel-r values in shallow $(10-40 \mathrm{~cm})$ soil depths, while the Mantel-r of soil moisture at deeper 281 depths $(80$ and $100 \mathrm{~cm}$ ) showed significant negative relationships with elevation and VDS (Fig.

282 3). This indicates that soil moisture patterns in deep depths are least organized across time in 283 higher elevations. All of the correlations between the terrain variables and soil moisture 284 autocorrelation at shallow depths consistently suggest that areas with steeper slopes and low 285 upslope contributing area have the lowest temporal structure in shallow soil moisture patterns. The temporal autocorrelation analysis showed varying degrees to which different terrain 287 variables are correlated to temporal soil moisture autocorrelation over different depths. Just as in 288 Canton et al. (2004), we found a significant relationship between vertical distance to stream 289 channel and temporal soil moisture patterns across all but the deepest soil depth, but our results 290 differ form Canton et al. (2004) in that we found no correlation with surface curvature at any 291 depths but did find significant and high correlations between soil moisture and local slope value. 292 The range of Mantel-r values at different depths reveal that the lowest values exist at $10 \mathrm{~cm}$ and 293 steadily increase on average through the lower depths. This reinforces the Takagi and Lin (2011) 
294 catchment-scale temporal soil moisture variation analysis, where the highest variation of soil 295 over time occurred in shallower depths.

296

297

298

299

300

301

302

303

304

305

306

307

308

309

310

311

312

313

314 of Park and van de Giesen (2004) (Fig. 6a). The Berks soil spread farther out from each concave

315 hillslope in the predicted soil map. The Blairton soil spanned a greater distance from where it 316

Based on the results from analyzing temporal autocorrelation of soil moisture across the catchment with terrain variables (Fig. 3), we chose local slope (Fig. 2a), upslope contributing area (Fig. 2d), VDS (Fig. 2c), plus depth to bedrock (Fig. 2b) to predict the distribution of various soil types in the catchment (see Section 2.5). The TWI and elevation variables are highly correlated with upslope contributing area and VDS, respectively, which means they do not offer new information for classifying soil type. The area directly around the stream channel (VDS = 0) is important to characterize for the Ernest soil type and TWI is a complex variable made up of slope and upslope contributing area. Therefore, we chose not to use elevation or TWI in the predictive soil mapping.

The Random Forest analysis uncovered that depth to bedrock is the most important variable for classifying soil types in the Shale Hills catchment, followed by upslope contributing area, VDS, and local slope (Fig. 4). Our predicted soil map (Fig. 5a) did a reasonable job in identifying various soil types, with an average classification error of $14.2 \%$. The Weikert (3.9 $\%$ error) and Ernest (9.1\% error) soil types were predicted the best during the Random Forest validation. The most noticeable difference between the predicted soil map (Fig. 5a) and the field surveyed soil map (Fig. 1) was the reduced coverage of the Rushtown soil in favor of the Berks soil in the northeastern part of the catchment. The predicted spatial pattern of the Rushtown soil in this part of the catchment resembled that of a concave hillslope as delineated using the method connected with the Ernest soil eastward along the valley in the predicted soil map, as compared 
317 to the field soil map. The slope class map (Fig. 5b) was then overlaid on the predicted soil map

318 (Fig. 5a), which resulted in seven distinct soil-terrain units (Fig. 5c). In comparison, five

319 landform units were generated for the Shale Hills (Fig. 6a) by using the relationship between

320 surface curvature and log-transformed upslope contributing area (Fig. 6b).

321

When comparing the different catchment stratification schemes for estimating soil

322 moisture content for our second objective, we found that the combined soil-terrain units

323 consistently outperform the landform unit map and the field soil map at most depths, as shown

324 with multiple time-series of $\mathrm{R}^{2}$ values (Fig. 7). The field soil map did a better job at predicting

325 soil moisture content than the landform unit map across all depths and did equally well as the

326 soil-terrain units at the $10 \mathrm{~cm}$ depth over time. The $\mathrm{R}^{2}$ time-series reveal that predictive power of

327 both the combined soil-terrain units and soil type tends to increase with soil depth but seemed to

328 decrease with depth for the landform unit approach. The total amount of measurements varied

329 for each collection date, but very weak and generally negative correlations between the number

330 of measurements and $\mathrm{R}^{2}$ exist for all systems. At deeper depths $(80-100 \mathrm{~cm})$ soil type and soil-

331 terrain units have very weak positive correlations with the number of measurements and $\mathrm{R}^{2}$. All

332 of the systems had significant and moderately high positive correlations with catchment averaged

333 moisture and $\mathrm{R}^{2}$ in the $10 \mathrm{~cm}$ depth, but landform units and soil-terrain units had weak but

334 negative correlations with catchment averaged moisture and $\mathrm{R}^{2}$ in the $40 \mathrm{~cm}$ depth (data not

335 shown).

The $\triangle$ AIC results shown in Fig. 8 also support the above results. On average, combined

337 soil-terrain units outperform soil type at $20-100 \mathrm{~cm}$ depths and outperform landform units over

338 all the monitored depths. From the AIC results, soil-terrain units do better than soil type for most

339 measurement dates at $20-100 \mathrm{~cm}$ depths. This could be due to the fact that soil-terrain units are 
340 better at differentiating the hillslope by slope class more effectively and as a result characterize

341 soil moisture patterns caused by processes that vary across a slope gradient, such as horizontal,

342 or 'lateral', hydraulic conductivity rates.

Our stratification analysis revealed that either soil-terrain units or soil type are favorable

344 choices for characterizing soil moisture patterns over landform units in the Shale Hills

345 catchment, and this is supported by both $\mathrm{R}^{2}$ and AIC model fit diagnostics. In terms of

346 comparing soil-terrain units with soil type, we do acknowledge that $\mathrm{R}^{2}$ is at least slightly biased

347 in favor of soil-terrain units, since there are two more units (i.e., categories) in the soil-terrain

348 stratification than soil type, but the AIC actually penalizes the soil-terrain units for having two

349 additional regression coefficients.

350

351

352

353

354

355

356

357

358

359

360

361

A further within-stratification analysis of the variance or standard error of soil moisture

within each unit over time may reveal the capability of each unit in representing hydrologic

dynamics across different catchment wetness conditions. The stratification systems presented in this paper could also be used to parameterize a spatially distributed hydrologic model, and the stratification system that enables such a model to most accurately characterize spatial soil moisture patterns and predict catchment discharge would be best suited for hydrologic modeling applications. An extension of this analysis presented in this paper could also be conducted in other catchments that have an in situ soil moisture monitoring network and detailed soil type information. 


\section{Conclusion}

Integrating soil type and terrain information to stratify the catchment captured soil moisture variation reasonably well in the Shale Hills catchment. From the validation using in

364 situ soil moisture data across the catchment, our results showed that soil features provided an

365 added value when used with terrain attributes in stratifying the catchment into areas with similar

366 soil moisture dynamics. We found that depth to bedrock, upslope contributing area, topographic

367 wetness index, and local slope were highly correlated with soil moisture variation at near-surface

368 depths $(10,20$, and $40 \mathrm{~cm})$, while elevation and vertical distance to stream were significantly

369 related to the relatively stable patterns of soil moisture found in the deeper depths (80 and 100

$370 \mathrm{~cm})$. The combined soil-terrain attributes were able to predict a soil map similar to that

371 generated from an extensive field survey.

372 The soil-terrain stratification theme used in this study consistently characterized soil

373 moisture patterns across the catchment at all measured depths more accurately than the existing 374 stratification schemes based on the landform units and even the field soil survey for deeper soils.

375 The field soil survey outperformed the stratification based on the landform units across all soil

376 depths monitored. Given the common approach of using just terrain for catchment stratification,

377 our results suggest that soil types should be considered when stratifying landscapes into units of 378 similar soil hydrologic dynamics.

379

380 Acknowledgements

This research was supported in part by the USDA Higher Education Challenge

382 Competitive Grants Program (Grant 2006-38411-17202), the National Science Foundation

383 Hydrologic Sciences Program (grant \#EAR-1416881), and the National Science Foundation 
384 Critical Zone Observatory Program (\#EAR-0725019). This work was conducted in Penn State's

385 Stone Valley Forest, which is supported and managed by the Penn State's Forestland

386 Management Office in the College of Agricultural Sciences. Assistance in the field data

387 collections and maintenance from the Penn State Hydropedology Group is gratefully

388 acknowledged.

389

390

\section{References}

391 Band, L.E., Patterson, P., Nemani, R., and Running, S.W., 1993. Forest ecosystem processes at 392 the watershed scale: incorporating hillslope hydrology. Agricultural and Forest $393 \quad$ Meteorology 63, 93-126.

394 Beven, K. J., and Kirkby, M. J., 1979. A Physically Based, Variable Contributing Area Model of 395 Basin Hydrology. Hydrological Sciences Bulletin 2, 43-69.

396 Blöschl, G., and Sivapalan, M., 1995. Scale Issues in Hydrological Modelling: a review. 397 Hydrological Processes 9, 251-290.

398 Breiman, L., 2001. Random Forests. Machine Learning 45, 5-32.

399 Burnham, Kenneth P., and David R. Anderson. 2002. Model Selection and Multimodel $400 \quad$ Inference. 2nd ed. New York, USA: Springer.

401 Canton, Y., Sole-Benet, A., and Domingo, F. 2004. Temporal and spatial patterns of soil 402 moisture in semiarid badlands of SE Spain, Journal of Hydrology 285, 199-214. 
Conrad, O., Bechtel, B., Bock, M., Dietrich, H., Fischer, E., Gerlitz, L., Wehberg, J., Wichmann, V., and Böhner, J. 2015. System for Automated Geoscientific Analyses (SAGA) v. 2.1.4, Geoscience Model Development 8, 1991-2007.

Devito, K., Creed, I., Gan, T., Mendoza, C., Petrone, R., Silins, U., and Smerdon, B., 2005. A Framework for Broad-scale Classification of Hydrologic Response Units on the Boreal Plain: Is Topography the Last Thing to Consider? Hydrological Processes 19, 1705-1714.

Diggle, P.J., and Ribeiro Jr., P.J., 2002. Bayesian inference in Gaussian model-based geostatistics. Geographical and Environmental Modelling 6, 129-146.

Dooge, J.C.I., 1986. Looking for Hydrologic Laws. Water Resources Research 22, 46-58.

Gharari, S., Hrachowitz, M., Fenicia, F., and Savenije, H.H.G., 2011. Hydrological Landscape Classification: Investigating the Performance of HAND Based Landscape Classifications in a Central European Meso-scale Catchment. Hydrology and Earth System Sciences 15, 32753291.

Gomez-Plaza, A., Martinez-Mena, M., Albaladejo, J., and Castillo, V.M., 2001. Factors regulating spatial distribution of soil water content in small catchments. Journal of Hydrology 253, 211-226.

Goslee, S.C., and Urban, D.L., 2007. The ecodist package for dissimilarity-based analysis of ecological data. Journal of statistical software 22, 1-19.

Guo, X., and Si, B.C., 2008. Characterizing LAI Spatial and Temporal Variability Using a Wavelet Approach. The International Archives of the Photogrammetry, Remote Sensing and Spatial Information Sciences 37, 31-34. 
424 Isaaks, E.H., and Srivastava, R.H., 1989. Applied Geostatistics 2, New York, Oxford University $425 \quad$ Press.

426 Leavesley, G.H., and Stannard, L.G., 1990. Application of remotely sensed data in a distributed-

427 parameter watershed model. In Proc. Workshop on Applications of Remote Sensing in

428 Hydrology, 47-68.

429 Legendre, P., and Fortin M. J. 1989. Spatial pattern and ecological analysis. Plant Ecology

$430 \quad 80: 107-138$.

431 Legendre, P., and Legendre L. 1998. Numerical ecology. Elsevier, Amsterdam.

432 Lin, H., 2006. Temporal Stability of Soil Moisture Spatial Pattern and Subsurface Preferential 433 Flow Pathways in the Shale Hills Catchment. Vadose Zone Journal 5, 317-340.

434 Lin, H., Kogelmann, W., Walker, C., and Bruns, M.A., 2006. Soil Moisture Patterns in a 435 Forested Catchment: A Hydropedological Perspective. Geoderma 131, 345-368.

436 Mantel, N., 1967. The Detection of Disease Clustering and a Generalized Regression Approach. 437 Cancer Research 27, 209-220.

438 McCune B, Grace J (2002) Analysis of ecological communities. MjM Software, Gleneden $439 \quad$ Beach, Oregon

440 Moore, I.D., Grayson, R.B., and Ladson, A.R., 1991. Digital Terrain Modeling: A Review of 441 Hydrological, Geomorphological, and Biological Applications. Hydrological Processes 5, 344230. 
443 Naithani, K.J., Baldwin, D., Gaines, K.P., Lin, H., and Eissenstat, D.M., 2013. Spatial 444 Distribution of Tree Species Governs the Spatio-Temporal Interaction of Leaf Area Index $445 \quad$ and Soil Moisture Across a Forested Landscape. PLoS ONE 8.

446 Naithani, K. J., Ewers, B. E., Adelman, J. D., and Siemens, D. H. 2014. Abiotic and biotic 447 controls on local spatial distribution and performance of Boechera stricta. Functional Plant $448 \quad$ Ecology 5, 348.

449 Odeh, I.O.A., McBratney, A.B., and Chittleborough, D.J., 1995. Further results on prediction of $450 \quad$ soil properties from terrain attributes: heterotopic cokriging and regression $451 \quad$ kriging. Geoderma 67, 215-226.

452 Olaya, V. and Conrad, O., 2009. Geomorphometry in SAGA. Developments in Soil Science 33, $453 \quad 293-308$.

454 Park, S.J., and van de Giesen, N., 2004. Soil-landscape Delineation to Define Spatial Sampling 455 Domains for Hillslope Hydrology. Journal of Hydrology 295, 28-46.

456 Pauwels, V., Hoeben, R., Verhoest, N.E.C., and De Troch, F.P., 2001. The Importance of the 457 Spatial Patterns of Remotely Sensed Soil Moisture in the Improvement of Discharge 458 Predictions for Small-scale Basins through Data Assimilation. Journal of Hydrology 251, 88$459 \quad 102$.

460 Qiu, Y., Fu, B., Wang, J., and Chen, L., 2001. Spatial variability of soil moisture content and its 461 relation to environmental indices in a semi-arid gully in catchment of the Loess Plateau., 462 China. Journal of Arid Environments 49, 723-750. 
463 R Development Core Team, 2013. R: A language and environment for statistical computing. R $464 \quad$ Foundation for Statistical Computing, Vienna, Austria.

465 Ribeiro Jr, P.J., and Diggle, P.J., 2001. geoR: A package for geostatistical analysis. R News 1, $466 \quad 14-18$.

467 Soil Survey Division Staff, 1993. Soil Survey Manual, U.S. Dept. Agricultural Handbook 18. $468 \quad$ U.S. Gov. Printing Office, Washington, DC.

469 Takagi, K., and Lin, H.S., 2012. Changing controls of soil moisture spatial organization in the $470 \quad$ Shale Hills Catchment. Geoderma 173, 289-302.

471 Tarboton, D.G., 1997. A New Method for the Determination of Flow Directions and Upslope 472 Areas in Grid Digital Elevation Models. Water Resources Research 33, 309-319.

473 Uuemaa, E., Roosaare, J., Kanal, A., and Mander, Ü. 2008. Spatial correlograms of soil cover as 474 an indicator of landscape heterogeneity. Ecological Indicators 8, 783-794.

475 Venables, W.N., and Ripley, B.D., 2002. Modern Applied Statistics with S., fourth edition, $476 \quad$ Springer.

477 Western, A.W., Grayson, R.B., Bloschl, G., Willgoose, G.R., and McMahon, T.A., 1999. 478 Observed spatial organization of soil moisture and its relation to terrain indices. Water $479 \quad$ Resources Research 35, 797-810.

480 Williams, C.J., McNamara, J.P., and Chandler, D.G., 2009. Controls on the temporal and spatial 481 variability of soil moisture in a mountainous landscape: the signature of snow and complex $482 \quad$ terrain. Hydrologic and Earth System Sciences 13, 1325-1336. 
483 Winter, T.C., 2001. The Concept of Hydrologic Landscapes. Journal of the American Water $484 \quad$ Resources Association 37, 335-349.

485 Yu, X., Duffy, C., Baldwin, D., and Lin, H., 2014. The role of macropores and multi-resolution 486 soil survey datasets for distributed surface-subsurface flow modeling. Journal of Hydrology $487 \quad 516,97-106$.

488 Zevenbergen, L.W., and Thorne, C.R., 1987. Quantitative analysis of land surface 489 topography. Earth surface processes and landforms 12, 47-56. 
491 Table 1. List of key data used in this study.

\begin{tabular}{|c|c|c|}
\hline Section & Variable & Use in This Study \\
\hline $\begin{array}{l}2.2,2.5 \\
2.6\end{array}$ & \begin{tabular}{|l} 
Volumetric soil moisture content $\left[\mathrm{cm}^{3} \mathrm{~cm}^{-3}\right]$ \\
(66 measurement dates; up to 106 locations)
\end{tabular} & $\begin{array}{l}\text { Calculating temporal autocorrelation across the catchment } \\
\text { Validating catchment stratification schemes }\end{array}$ \\
\hline 2.3 & Soil survey samples (289) & Creating detailed soil map from field survey \\
\hline 2.4 & $\begin{array}{l}\text { Soil depth from auger measurements }(318) \\
\text { [m] } \\
\text { 1-m resolution LiDAR digital elevation model }\end{array}$ & $\begin{array}{l}\text { Creating depth to bedrock map } \\
\text { Creating terrain variables }\end{array}$ \\
\hline 2.5 & $\begin{array}{l}\text { Mantel-r for soil moisture content } \\
\text { (69 sites; up to } 5 \text { different depths) } \\
\text { Subset of soil samples from TDR sites (47) }\end{array}$ & $\begin{array}{l}\text { Correlating soil hydrologic dynamics to terrain for variable } \\
\text { selection used in stratification } \\
\text { Creating detailed soil map with Random Forest and terrain data }\end{array}$ \\
\hline
\end{tabular}

492 
Table 2. Summary of the three stratification schemes investigated in this study and related inputs of terrain and soil attributes used in each method.

\begin{tabular}{|c|c|c|c|c|c|c|c|c|c|}
\hline \multirow{2}{*}{$\begin{array}{l}\text { Stratification } \\
\text { Method }\end{array}$} & \multicolumn{6}{|c|}{ Terrain Inputs } & \multicolumn{2}{|c|}{ Soil Inputs } & \multirow{2}{*}{$\begin{array}{c}\text { Number of } \\
\text { Units }\end{array}$} \\
\hline & UCA* & Curvature & TWI* & VDS* & Slope & Slope Class & $\begin{array}{l}\text { Field Soil } \\
\text { Samples }\end{array}$ & DtB* & \\
\hline I. Landform Unit & $\begin{array}{c}\text { Terrain } \\
\text { Characterization }\end{array}$ & \begin{tabular}{c|} 
Terrain \\
Characterization
\end{tabular} & -- & -- & $\begin{array}{c}\text { Refined Summit } \\
\text { Unit }\end{array}$ & -- & -- & -- & 5 \\
\hline II. Field Soil Survey & -- & -- & -- & -- & -- & -- & $\begin{array}{l}\text { USDA (Order I) } \\
\text { Field Survey }\end{array}$ & $\begin{array}{l}\text { Refine Soil } \\
\text { Boundaries }\end{array}$ & 5 \\
\hline $\begin{array}{l}\text { III. Predicted soil Map } \\
\text { + Slope Class }\end{array}$ & $\begin{array}{l}\text { Random Forest } \\
\text { Covariate }\end{array}$ & Estimate DtB & Estimate DtB & $\begin{array}{c}\text { Random Forest } \\
\text { Covariate }\end{array}$ & $\begin{array}{l}\text { Random Forest } \\
\text { Covariate }\end{array}$ & $\begin{array}{l}\text { Final Unit } \\
\text { Stratification }\end{array}$ & $\begin{array}{c}\text { Training for } \\
\text { RF Classification }\end{array}$ & Random Forest & 7 \\
\hline
\end{tabular}

* UCA = Upslope Contributing Area, TWI = Topographic Wetness Index, VDS = Vertical distance to stream, DtB = Depth to Bedrock 
499 Figure 1. Map of soil types across the Shale Hills catchment based on detailed field soil survey. 500 Locations with soil moisture data collection (TDR sites) are shown with symbols corresponding 501 to different soil types. The stream is shown in white, and 3-m elevation contours are shown in 502 grey.

503 Figure 2. Maps of terrain attributes derived from the digital elevation model created from 1-m 504 resolution LiDAR: (a) local slope $\left[\mathrm{m} \mathrm{m}^{-1}\right]$, (b) depth to bedrock (DtB) [cm], (c) vertical distance 505 to stream (VDS) [m], (d) natural log-transformed upslope contributing area (UCA) [ln $\left.\left(\mathrm{m}^{2}\right)\right],(\mathrm{e})$ 506 topographic wetness index (TWI) [-], and (f) surface curvature [-].

507 Figure 3. Correlation matrix showing scatterplots of Mantel correlation coefficient (Mantel-r) of 508 soil moisture at five depths $(10-100 \mathrm{~cm})$ and terrain variables from all monitoring sites. 509 Correlation coefficients that are significant at $p<0.05$ are highlighted in red.

Figure 4. Bar plots of the difference in classification accuracy within a regression tree forest 511 when each variable is permuted. The higher the permutation error difference, the more important 512 the variable is for predicting soil types in the catchment.

513 Figure 5. Sequence of maps used in delineating combined soil-terrain units: (a) predicted soil 514 map based on a Random Forest supervised classification tree algorithm using LiDAR-derived 515 terrain and depth to bedrock as predictors, together with 47 soil samples (marked as ' $\mathrm{x}$ ' on the 516 map); (b) slope class map; and (c) combined soil-terrain units generated by overlaying the 517 predicted soil map with the slope class map. A total of 7 soil-terrain units are delineated (see the 518 color legend). 
519 Figure 6. Landform unit delineated using Park and van de Giesen (2004) method based on 520 surface curvature ( $\mathrm{Y}$ axis) and log-transformed upslope contributing area ( $\mathrm{X}$ axis): (a) the 521 resulting map showing 5 landform units across the catchment, and (b) scatterplot with points 522 marked in different colors according to the corresponding landform units in (a).

523 Figure 7. Comparison of time-series (2006 - 2010) of $\mathrm{R}^{2}$ values of generalized linear regression 524 modeling in estimating volumetric soil moisture content $\left[\mathrm{cm}^{3} \mathrm{~cm}^{-3}\right]$ across the catchment at 525 various depths: (a) $10 \mathrm{~cm}$, (b) $20 \mathrm{~cm}$, (c) $40 \mathrm{~cm}$, (d) $80 \mathrm{~cm}$, and (e) $100 \mathrm{~cm}$, based on three 526 stratification schemes: blue, combined soil-terrain units; red, soil types; and black, landform 527 units.

528 Figure 8. Boxplots of difference (between soil-terrain unit and other two startification schemes) 529 in Akaike's Information Criterion (AIC), which are associated with the generalized linear 530 regression models predicting volumetric soil moisture content $\left[\mathrm{cm}^{3} \mathrm{~cm}^{-3}\right]$ at $10 \mathrm{~cm}, 20 \mathrm{~cm}, 40$ $531 \mathrm{~cm}, 80 \mathrm{~cm}$, and $100 \mathrm{~cm}$ depths. The $\triangle \mathrm{AIC}$ is calculated by taking the difference between (1) 532 AIC from regression models that used soil type or landform unit stratification as predictors and 533 (2) AIC from the model using combined soil-terrain units as predictor (i.e., $\Delta \mathrm{AIC} \mathrm{Landform} \mathrm{Unit}=$ $\left.534 \mathrm{AIC}_{\text {Soil-terrain }}-\mathrm{AIC}_{\text {Landform Unit }} ; \Delta \mathrm{AIC}_{\text {Soil Type }}=\mathrm{AIC}_{\text {Soil-terrain }}-\mathrm{AIC}_{\text {Soil Type }}\right)$. Combined soil-terrain 535 units perform better than either soil type from field survey or landform unit, with negative $\Delta$ AIC 536 (zero $\triangle \mathrm{AIC}$ indicates no difference between the two models' predictive skill). The blue dashed 537 line indicates the mean $\triangle \mathrm{AIC}$ value for each boxplot. 


\section{Figure 1}

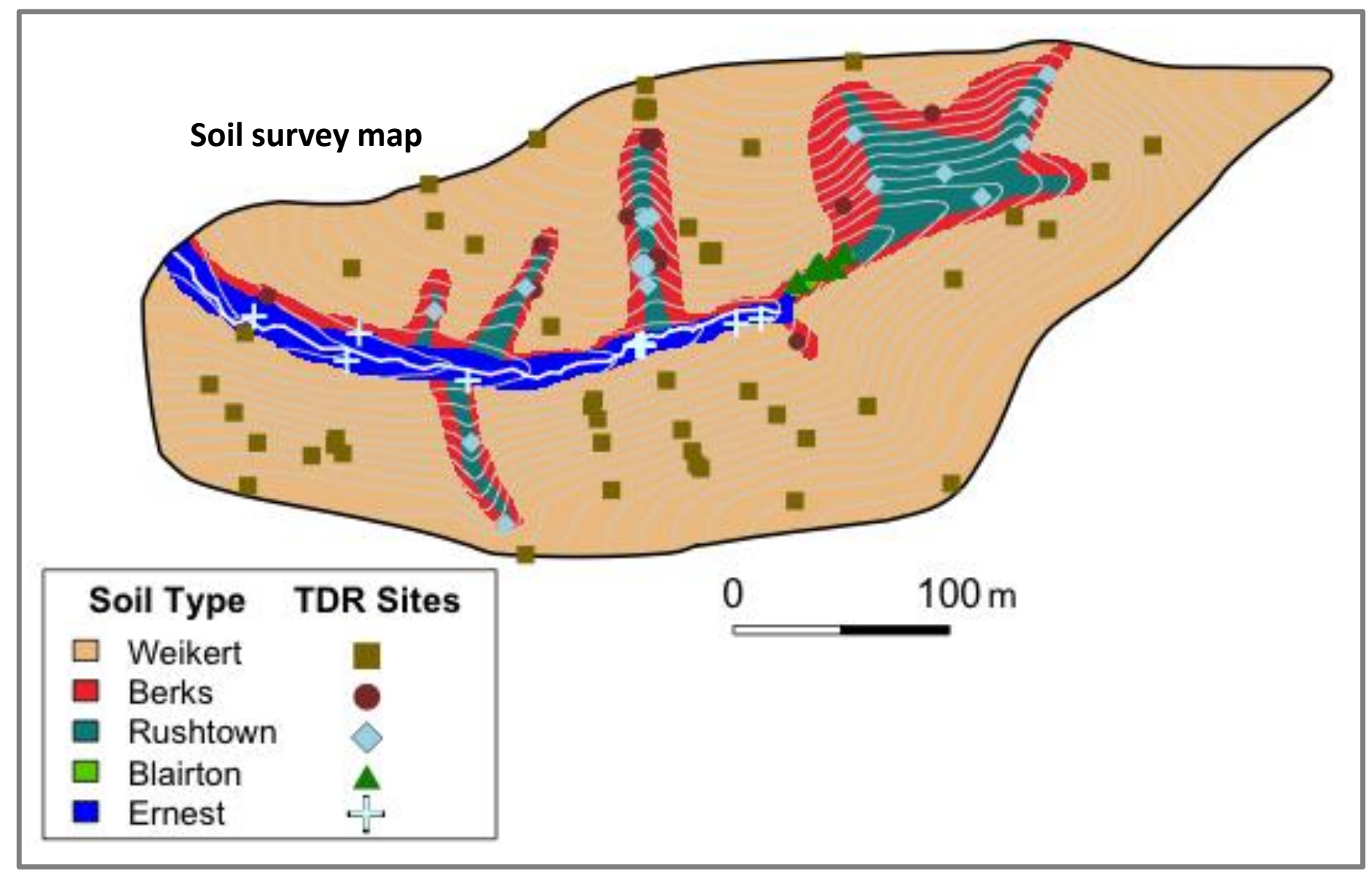




\section{Figure 2}

(a) Local slope
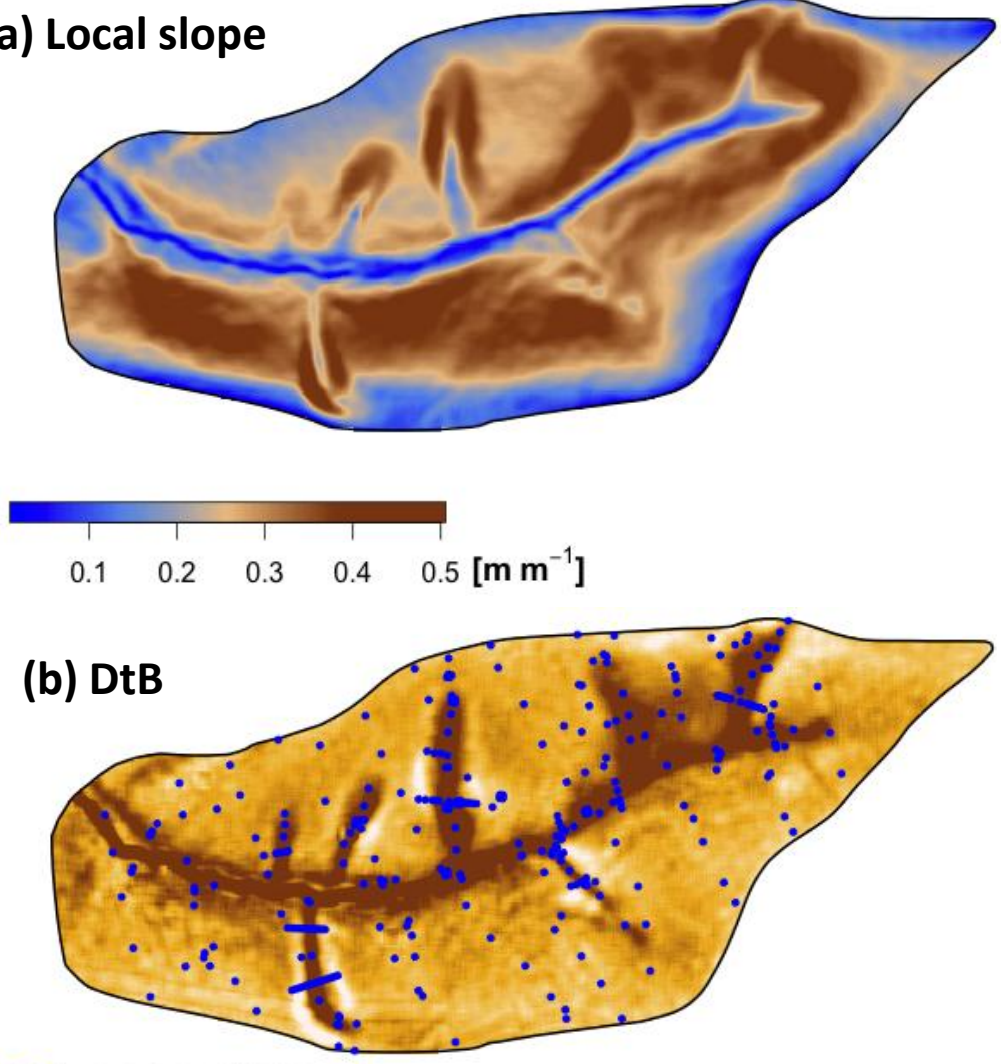

- Auger Locations
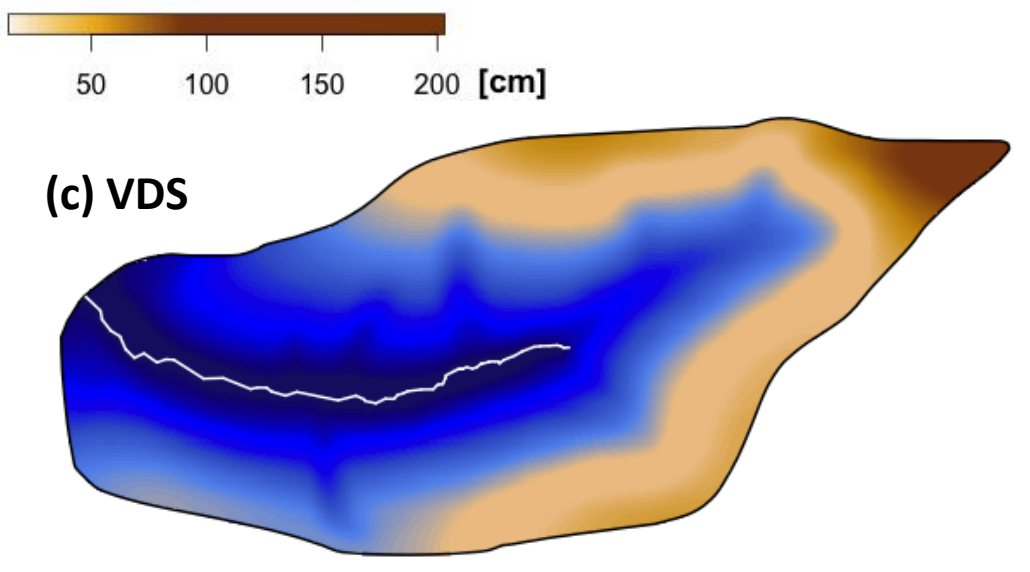

(d) UCA
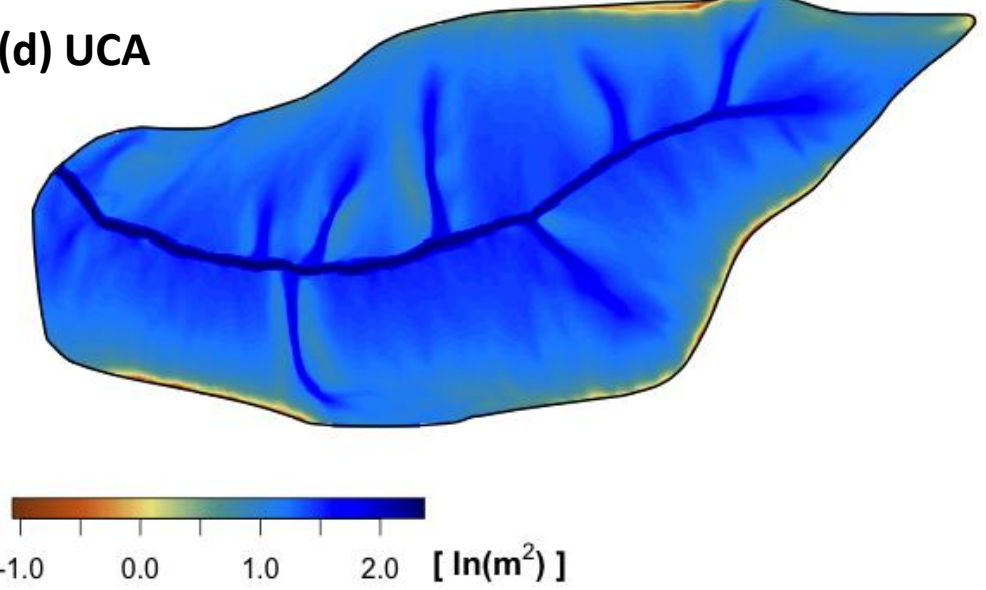

(e) TWI
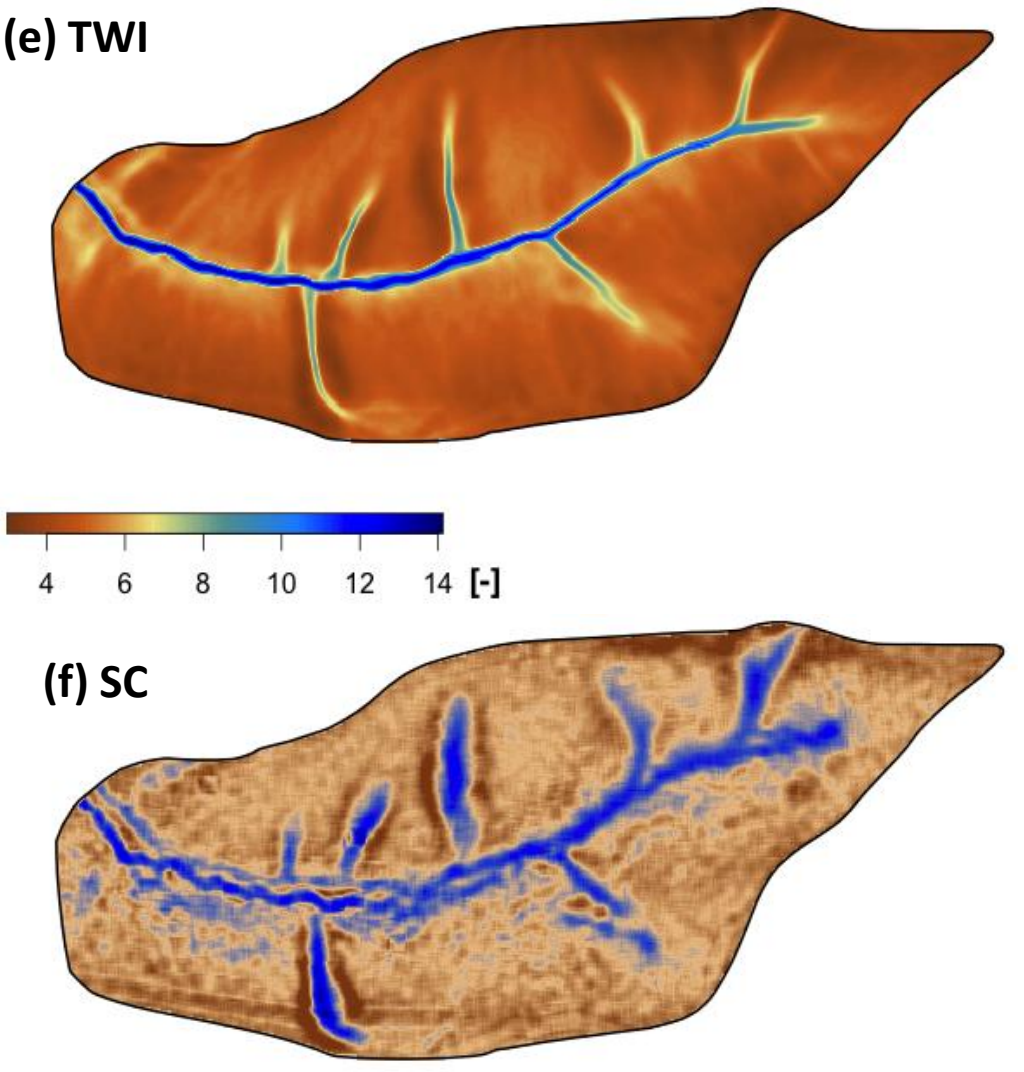

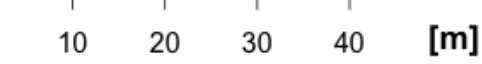

$\begin{array}{lllll}-0.10 & -0.05 & 0.00 & 0.05 & {[-]}\end{array}$ 


\section{Figure 3}

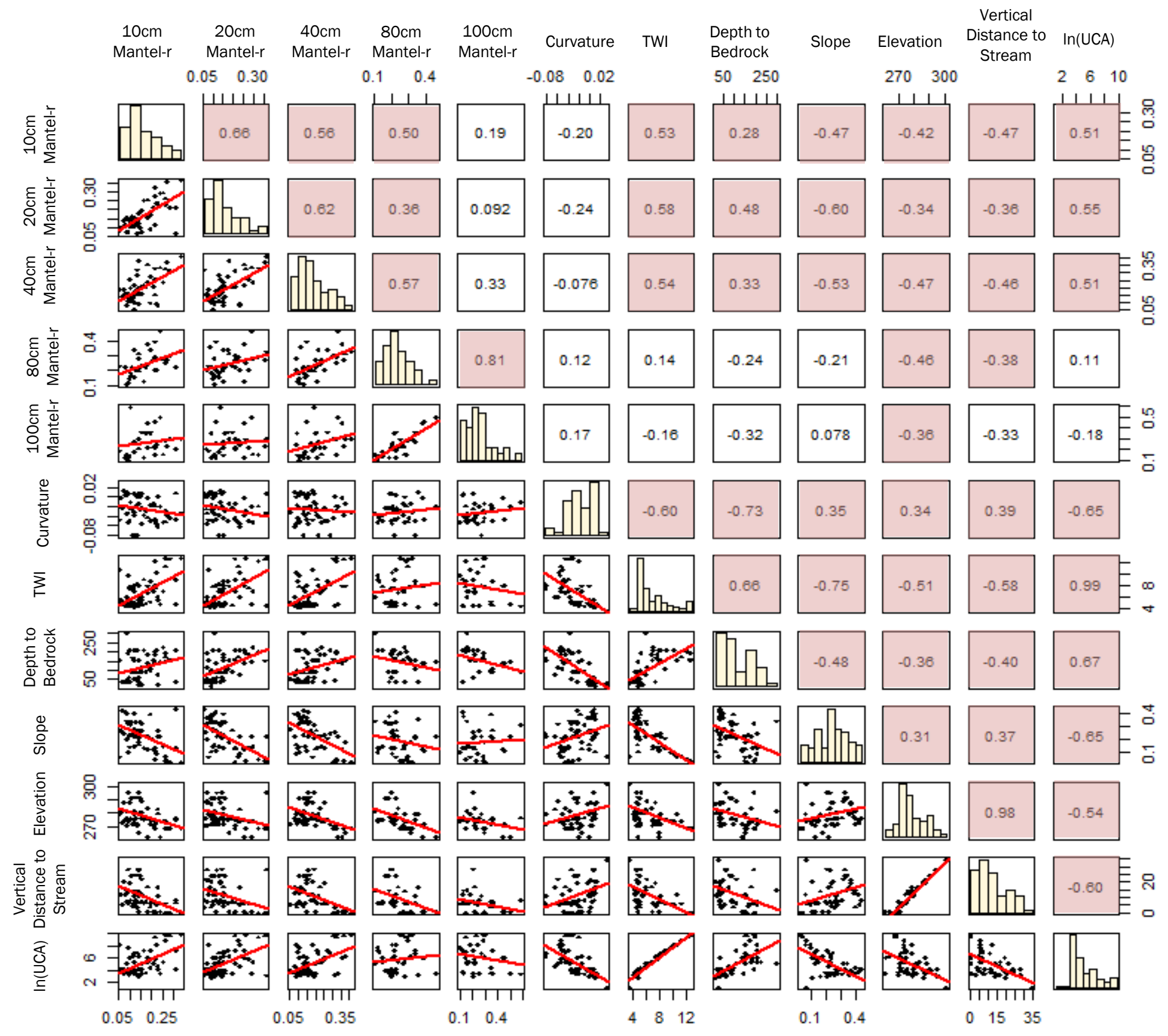


Figure 4

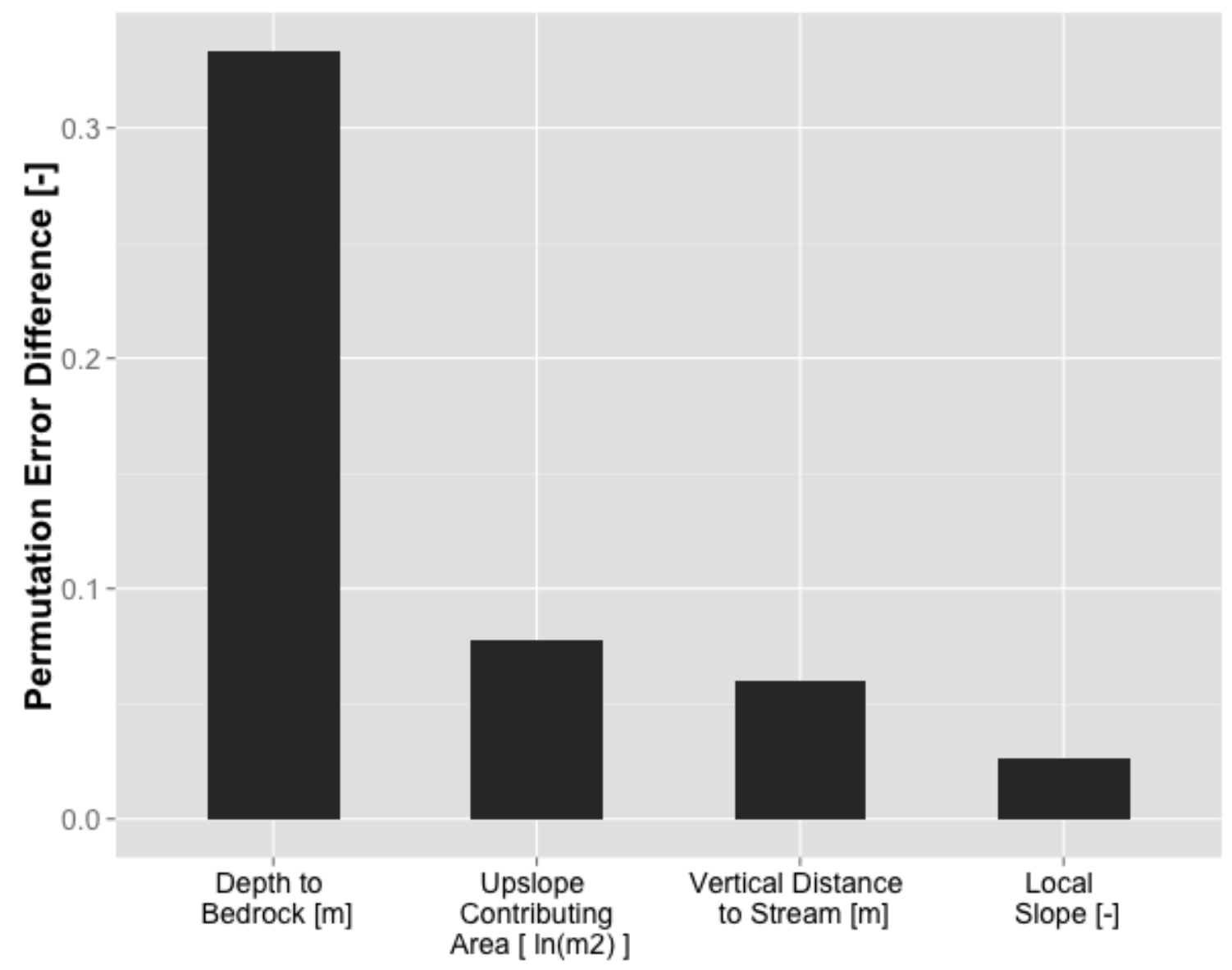




\section{Figure 5}

(a) Predicted Soil Map

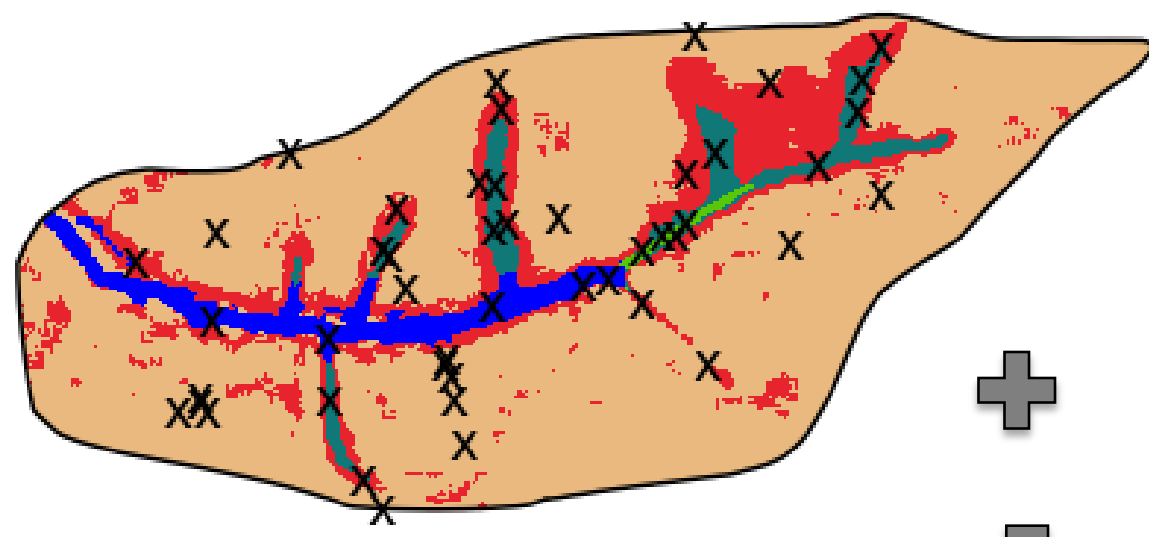

$\sqrt{5}$ (b) Slope Class Map

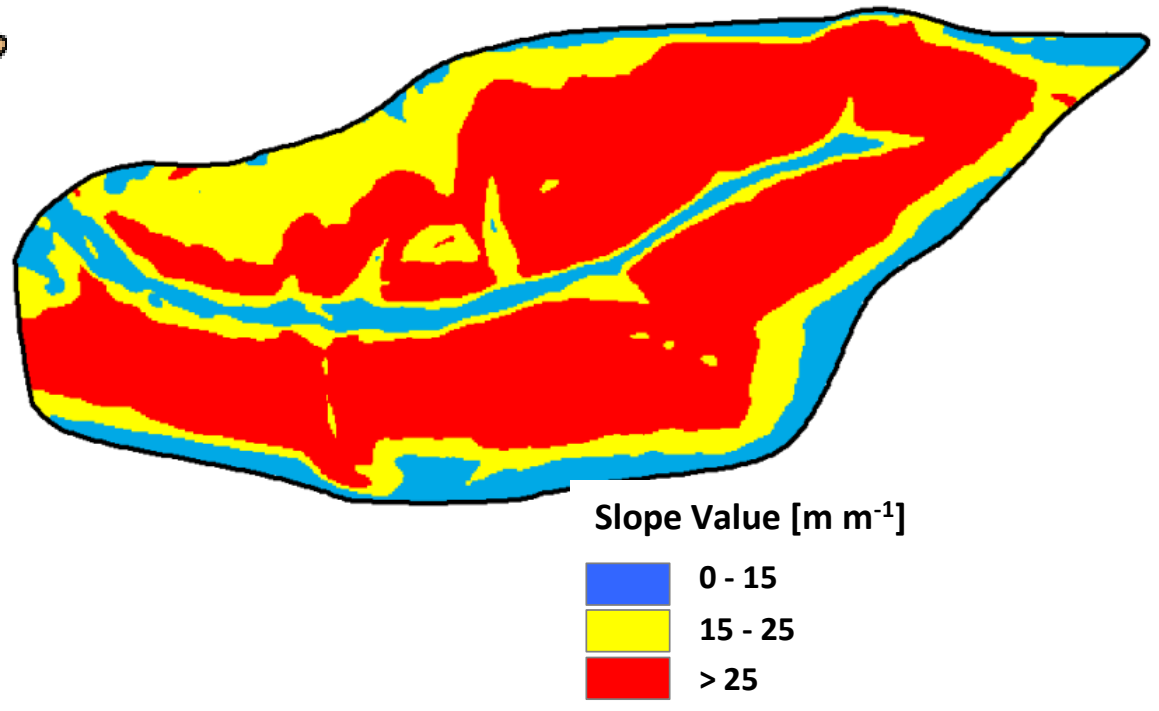

(c) Soil-Terrain-Unit Map

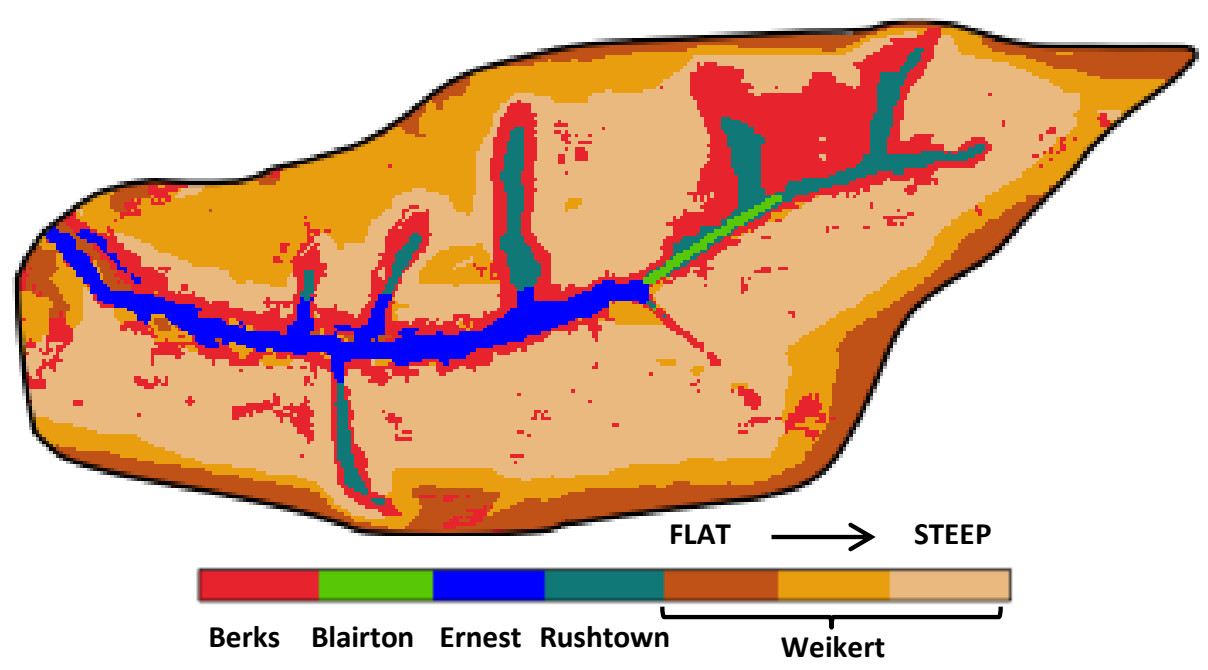




\section{Figure 6}

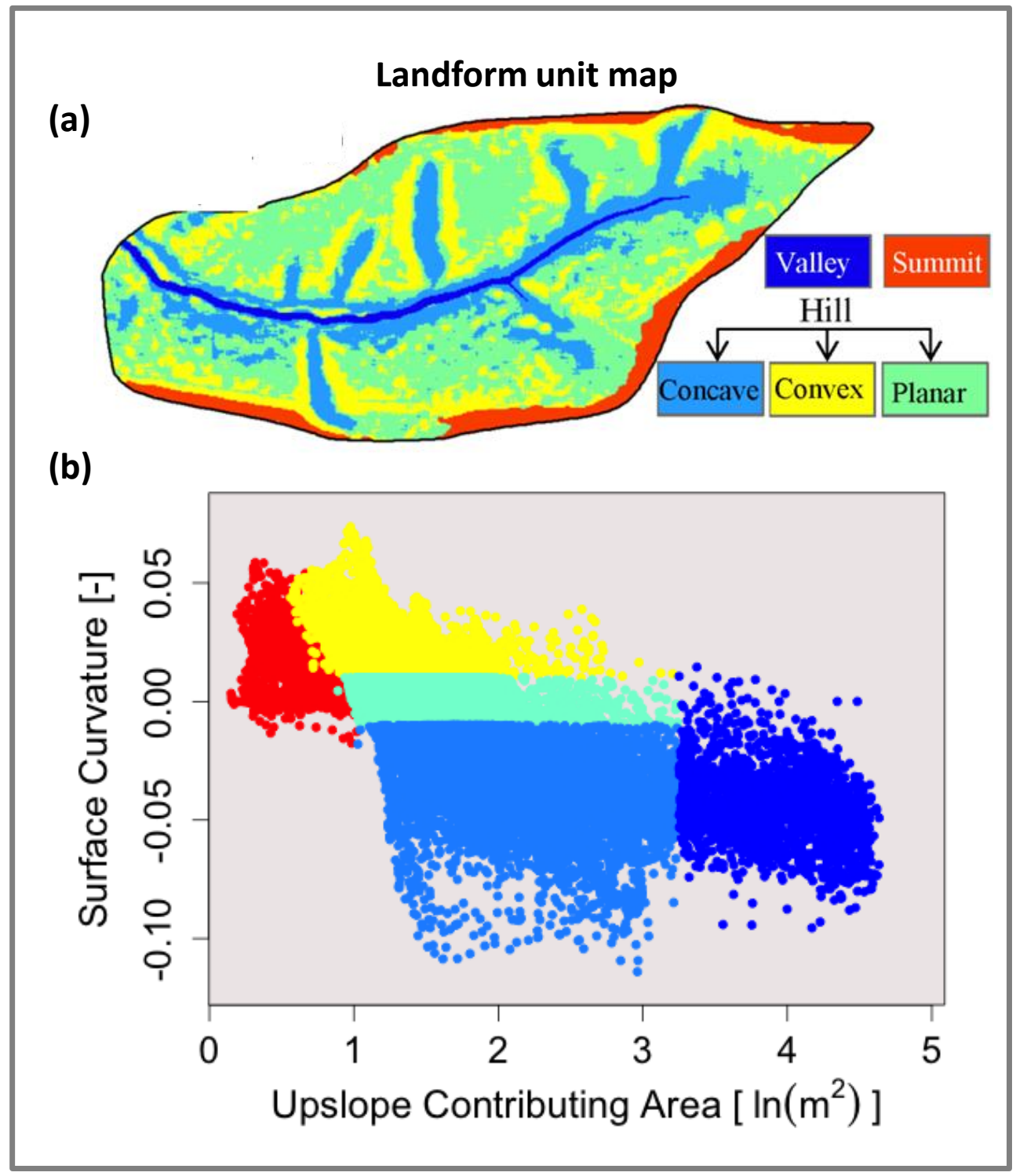




\section{Figure 7}
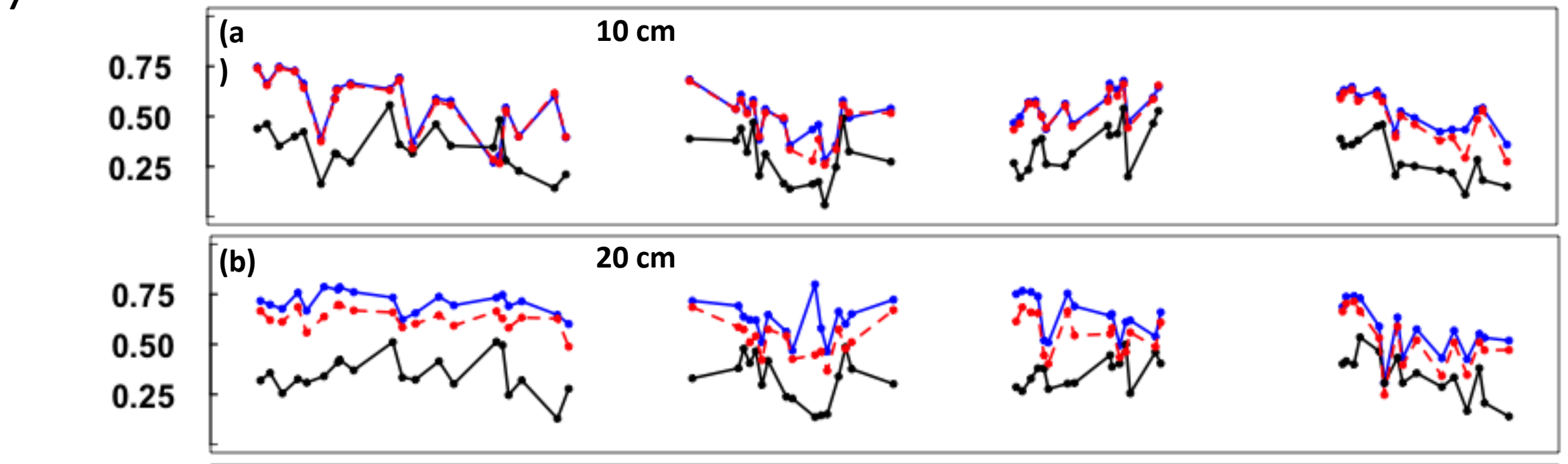

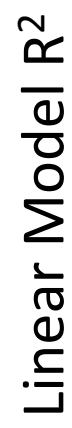
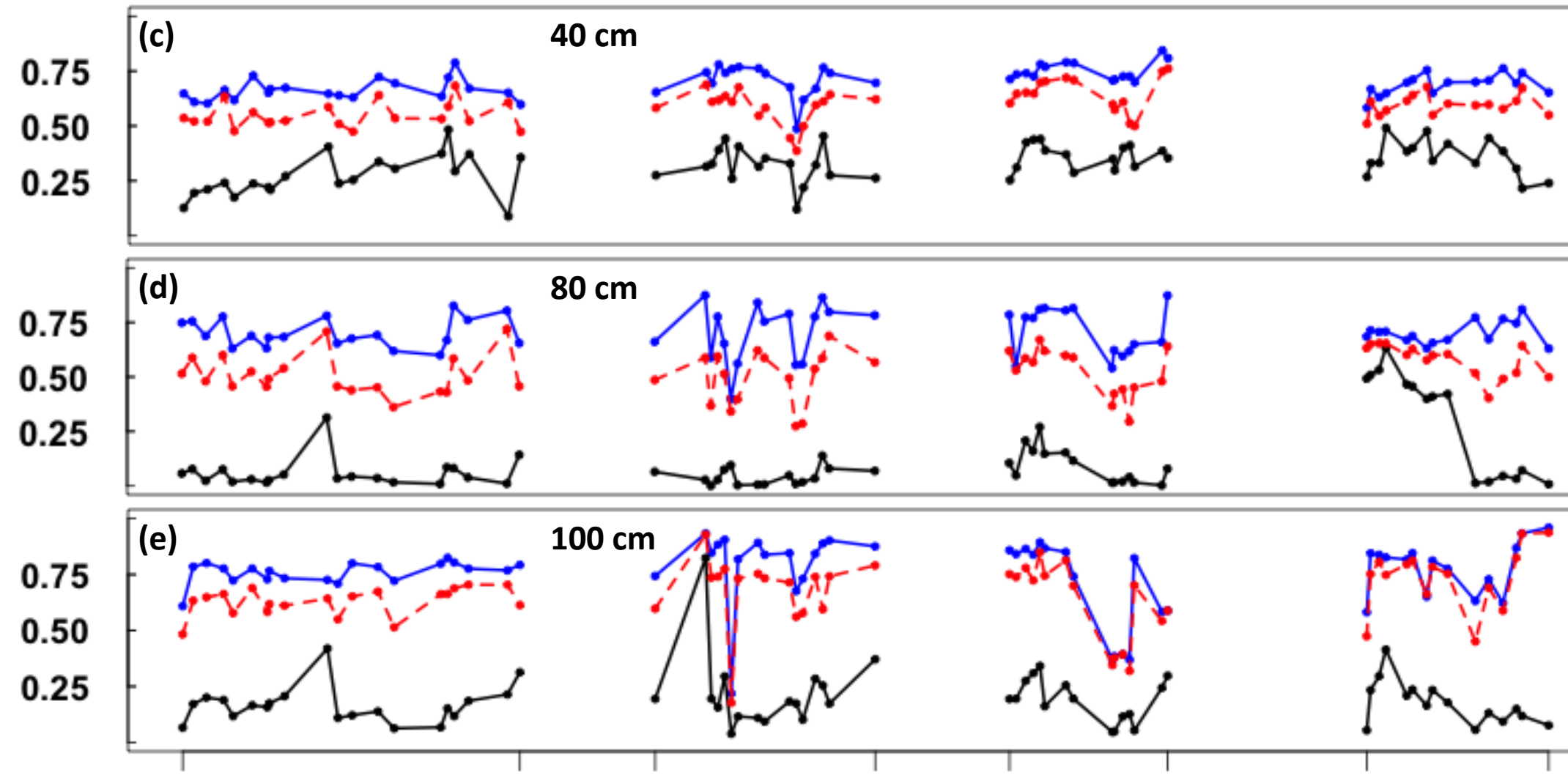

$80 \mathrm{~cm}$
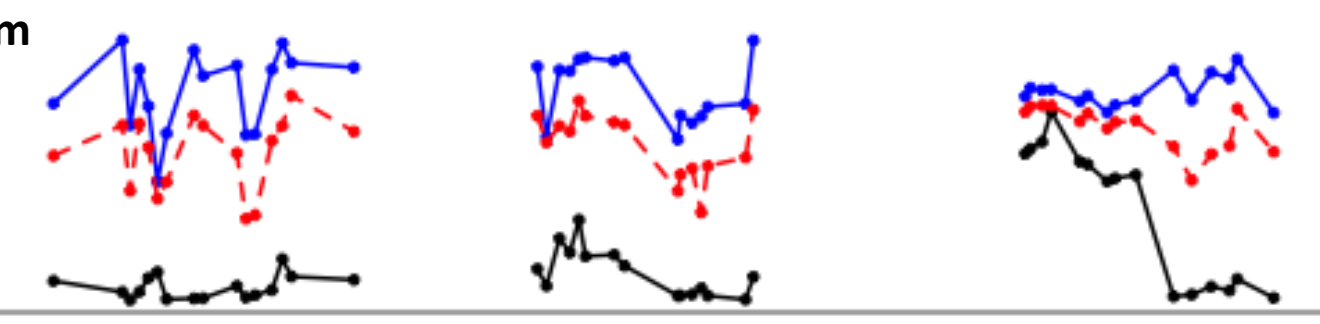


\section{Figure 8}

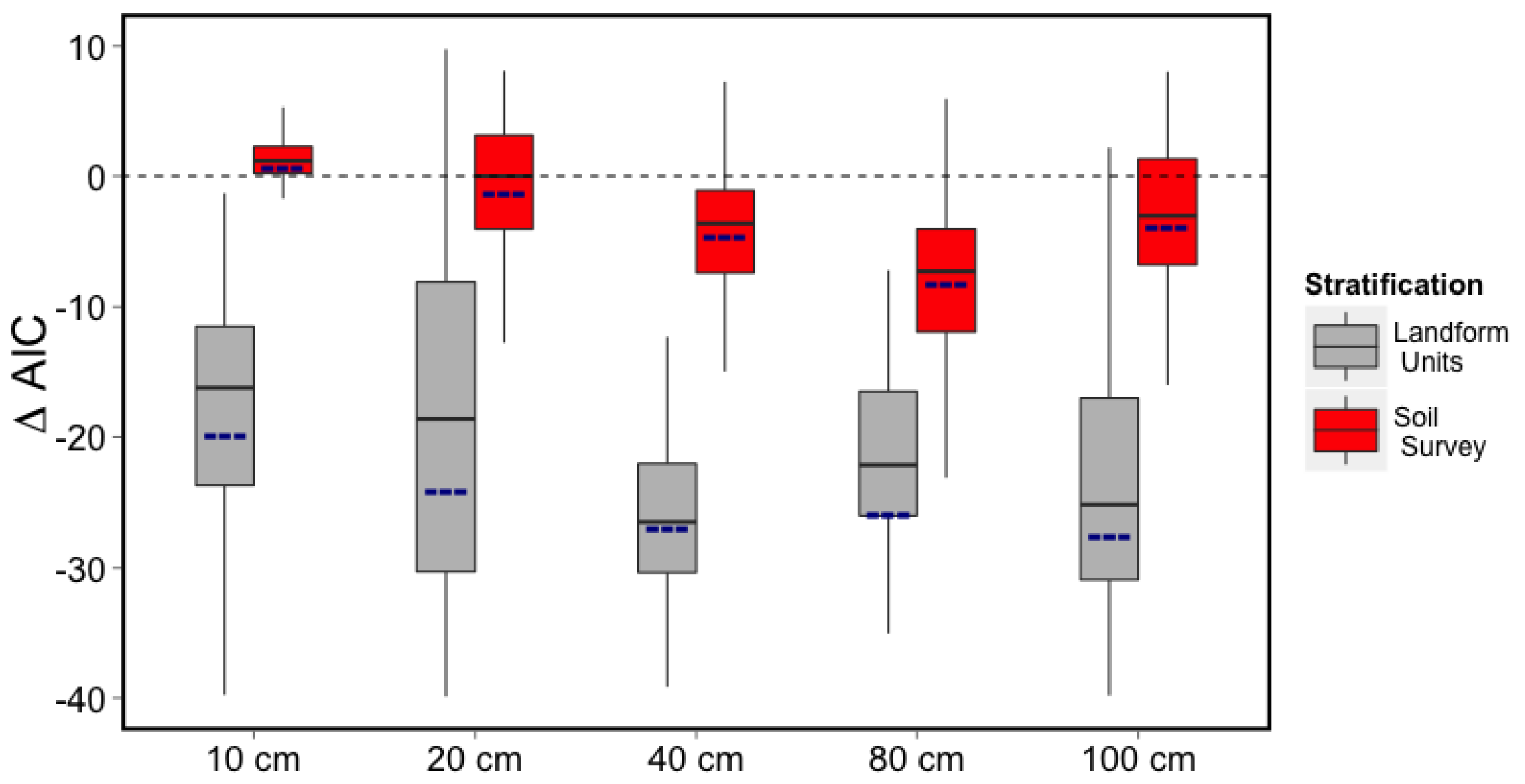

